\title{
Poverty Changes in Developing Countries
}

\author{
Gary S. Fields
}

\section{Introduction}

This chapter is concerned with measuring how the extent of poverty changes in a country over time. 'Poverty', as the term is used here, denotes the inability of an individual or a family to command sufficient resources to satisfy basic needs. ${ }^{1}$ The poverty line is a constant real amount below which people are said to be poor. The extent of poverty in a country is then based on variables such as the number who are poor and the extent of their resource shortfall.

This chapter treats three topics: how poverty is defined, how much poverty there is, and how the extent of poverty has changed over time. The ideal would be to be able to use an internationally comparable poverty

line (discussed in section 2) to construct a comprehensive poverty measure (defined in section 3) with which to determine how poverty has changed over time. But because the ideal is not now possible, the best we can do at present is to use country-specific poverty lines and noncomprehensive poverty measures. The evidence on this is summed up in section 4.

\section{How Is Poverty Defined?}

If an individual or a family is to be labelled 'poor' when they lack the resources to satisfy basic needs, the first task is to provide a workable definition of what it means for basic needs not to be satisfied. The usual approach is to define poverty in terms of a dollar or peso amount, termed 'the poverty line income' or simply 'the poverty line'.

If poverty is defined absolutely, a single time-invariant poverty line needs to be set in real terms. Once such a line has been determined, it is possible to calculate the extent of poverty according to that standard, both at any given time and over time. While there are different views about whether it makes sense to strive for a single international poverty line, such discussions are academic: different countries have different poverty lines and there is no choice but to accept this.

In those situations where the definition of poverty is still a matter of choice, the following considerations arise in setting a poverty line:

\section{Income or Consumption?}

In most countries, the basis for determining poverty is income. The reason for using income rather than consumption is a practical one: usually, income information is available and consumption information is not. However, when both are available, consumption is the better basis for determining who is poor and who is not. This is because income in any given month or year may be temporarily high or low; the family tries to smooth their consumption across periods by saving or dissaving as needed. For this reason, their consumption during the survey period is a better guide to their permanent standard of living than their current income. 
Sometimes we do not have information even on income (the sum of earned and nonearned income) but only on labour earnings. But decomposition studies have shown that the poor have very little income other than their earnings from wage employment or from selfemployment, so the omission of non-earned income is not too serious for determining poverty status. If only earnings information is available, it is therefore better to use it than not.

\section{Imputations?}

In many instances, the household surveys ask questions such as 'What was your income in pesos last week?' When the surveys are limited in this way, we have no choice but to use cash income as a basis for our poverty calculations. But sometimes non-cash income information is available. When it is, it would be desirable to include in consumption the monetary value of these items. Imputations may be made for food and other goods produced and consumed at home, basic goods provided free or at subsidised rates by the government (for example, free rations of the staple food), and non-wage fringe benefits provided by the employer (such as housing, meals, health care and old-age pensions).

\section{Choice of recipient unit}

The choice here is between the individual, the family and the household. ${ }^{2}$ If the basis for assessing poverty is a labour force survey, we have little choice but to take the individual as the recipient unit. But when individuals can be grouped into families or households, it is better to use the largerunits. This means that low-earning individuals are classified as non-poor if they are members of high-earning families, which would seem to be right.

\section{Adjustment for family size}

To take account of the fact that larger families have greater needs than small families, an adjustment needs to be made for family size. There are two ways of doing this. One is to set different poverty lines for different family sizes. For instance, the 1990 United States poverty line is $\$ 13,360$ for a family of four. But the adjustment for family size is non-linear: the line is $\$ 6,652$ for an unrelated individual and $\$ 17,835$ for a family of six. Making the family size adjustment non-linear in this way takes account of two things: economies of scale (it costs less than twice as much for two people to live together as it does for them to live separately) and different nutritional requirements for different types of individual (workers have higher consumption requirements than non-workers, adults higher than children and (possibly) men higher than women). I know of no developing country that has different poverty lines for families of different sizes.

What all developing countries do is to adjust for family size so that a single poverty line can be used for families of different sizes. The simplest way of making this adjustment is to express the poverty line on a per capita basis and to compare a given household's per capita income or consumption with that amount. Otherwise, differences in needs may be allowed for by making the family adjustment on an adult-equivalent basis. In some countries, for instance, men 
are counted with a weight of 1.0, women with a weight of 0.5 and children with a weight of 0.25. Such adjustments are controversial and, to some, offensive and should be undertaken with care.

In the absence of the kind of detailed budget studies that would permit different poverty lines to be drawn for families of different sizes, the per capita adjustment would appear to be the preferred alternative.

\section{Time period covered}

Most household surveys gather retrospective information on income or consumption. This raises the question of what the reference period should be. A balance must be struck between the desire for minimising recall and reporting error (which argues for a short reference period) and the desire to capture permanent rather than transitory living standards (which argues for a long reference period). What this balance is depends on the type of work people do. For casual workers, a year is probably too long a reference period and a day too short; a week or a month would be better. On the other hand, for farm households, whose income is seasonal, a year is the only sensible reference period. Flexibility is needed here.

\section{Regional differentiation}

In some countries, the cost of living varies widely from one part of the country to another. In such cases, it may be desirable to have separate poverty lines, say for rural as opposed to urban households, or for different states or regions. India and Costa Rica have both done this. But along with regionally distinct poverty lines comes also the need for regionally distinct inflation adjustments and regionally distinct imputations for home-produced or employerprovided goods and services. The gains may not be worth the cost.

\section{Adjusting for inflation}

The poverty line needs to be adjusted to reflect inflation. In some countries, an annual inflation adjustment is sufficient. However, in those with triple-digit inflation or high doubledigit inflation, adjustments must be made more frequently, perhaps monthly or even weekly.

In those countries where separate inflation factors are available for high-income, middleincome and low-income households, the low-income cost of living factor should be used to adjust the poverty line over time.

Otherwise, options are to use a national inflation rate or to use one or more components of that rate, for instance, the increase in the food-price index. Which to use depends upon the composition of the market basket used to construct the national consumer price index and the share of the poor's consumption devoted to food or other specific items.

\section{Not adjusting for growth}

One adjustment that should not be made is for economic growth. We want our poverty line to be an absolute one, hence constant in terms of real purchasing power. Increasing the poverty line by the growth rate would give us instead a measure of relative poverty - a very different concept and not the one we are after here. 
Based on these concepts, several attempts have been made to construct internationally comparable poverty lines, with the same concept(consumption), the same recipient unit (household) and the same dollar amount.

\section{The World Bank poverty line}

In its 1990 World Development Report, the World Bank defined poverty using two figures: US\$275 and \$370 per capita per year. The lower figure ('extreme poverty') corresponds to a poverty line for India, while the higher figure ('poverty') applies to a range of countries including Bangladesh, Egypt, India, Indonesia, Kenya, Morocco and Tanzania. Local currencies are converted to dollars using the Purchasing Power Parity rates.

\section{The IDB poverty line}

The Inter-American Development Bank defines poverty in terms of local currency. The line reflects the cost of a nutritionally-sound diet consistent with the food preferences of the poor in that country. The food cost is then multiplied by a factor which allows for expenditures on non-food items. This multiplier varies between 2.0 and 2.5 for different countries.

\section{The ECLA poverty line}

The Economic Commission for Latin America and the Caribbean (ECLA) has attempted to measure the extent of poverty in Latin America. Like the IDB, ECLA considers two factors when determining the poverty line: the cost of the basic food basket and the cost of non-food necessities. The basic food basket is determined by nutritional necessities, mainly the calorific value and protein content of food, as well as current dietary habits. The cost of non-food necessities is estimated to be equal to the cost of the basic food basket in each country, so that the 'poverty line' is double the basic food budget. The 'indigency line' is the amount needed just for food but not other items.

From this review, it is apparent that these organisations have followed essentially similar methodologies in deriving their poverty line. Many individual countries have also done this. In other countries, however, poverty is defined in a quite arbitrary way, for example, by reference to the country's minimum wage, which is determined politically rather than by any sort of scientific estimate of human needs. In this brief paper, space does not permit further discussion of country-specific poverty lines.

\section{How Much Poverty Is There? ${ }^{3}$}

Once we have defined who is poor and who is not, the next step is to aggregate the various poor households into some sort of measure which determines how much poverty there is, both in the country as a whole and among particular groups. The simplest poverty measure is the poverty head-count, which tells how many are poor. Using the internationally comparable 
poverty lines described in the previous section, the World Bank estimates that more than 1,100 million of the world's people are poor and more than 600 million extremely poor. Similarly, the United Nations reports that more than 1 billion people are absolutely poor in the world (Human Development Report 1990).

After the poverty head-count, the next simplest measure is the poverty head-count ratio. This is the proportion of households or individuals in poverty.

The poverty head-count and the poverty head-count ratio share a similar problem: they only indicate how many individuals or families are poor, but not how severe their poverty is. For this reason, it is also of interest to measure the average income shortfall of the poor - the higher it is, the more poverty there is.

In addition, another factor which is not picked up by the average income shortfall measure may also enter into poverty judgements, and that is the extent of income inequality among the poor. It might reasonably be said that poverty is increased by a disequalising transfer among the poor (that is, from a very poor person to a less poor person). Interpersonal comparability of utility along with diminishing marginal utility of income would yield this judgement. Thus, inequality among the poor ought also to be part of the definition of poverty.

Typically, data on poverty are calculated from published tabulations. From these, it is possible to estimate the poverty head-count ratio and the average income shortfall. Usually, in poverty reports, these two aspects of a country's poverty are presented separately. But the degree of income inequality among the poor is hard to estimate from published tabulations, because the tabulations typically include too few income categories among the poor.

Calculated in this way, the various poverty measures tell us about different aspects of a country's poverty, but not all at once. For this reason, they might be labelled as noncomprehensive poverty measures. The alternative, of course, is to look at comprehensive poverty measures which take account of all three of these components simultaneously. This can be done when the original income distribution data are available in computerised form.

One appealing comprehensive measure is the Sen poverty index:

$$
5=H\left[I+(1-I) G_{P}\right]
$$

where $\mathrm{H}$ is the poverty head-count ratio, $\mathrm{I}$ is the average income shortfall of the poor in percentage terms and Gp is the Gini coefficient of income inequality among the poor (Sen, 1976).

The Sen index is larger:

a. the higher the head-count ratio, for any given average income shortfall and Gini coefficient among the poor;

b. the higher the average income shortfall among the poor, for any given head-count ratio and Gini coefficient among the poor;

c. the higher the Gini coefficient among the poor, for any given head-count ratio and average income shortfall.

Another appealing comprehensive measure is the index suggested by Foster, Greer and Thorbecke (1984). This index, called the Pa index, is defined as:

$$
\mathrm{P}_{\mathrm{B}}=(1 / \mathrm{n}) £,[(\mathrm{z}-* \bullet) / *] ”
$$


where the term in brackets $[(\mathrm{z}-\mathrm{y} ;) / \mathrm{z}]$ is the difference between the poverty line $(\mathrm{z})$ and the income of the i'th poor household, expressed as a percentage of the poverty line, and the summation is over all poor people. The expression $[(\mathrm{z}-\mathrm{yi}) / \mathrm{z}]^{\mathrm{a}}$ is then the exponentiated income shortfall of the i'th household. This is then summed and divided by total population (n) to yield the index Pa. The values of a of particular interest are $\mathrm{a}=0,1$ and 2 .

Any value of a greater than 1 gives greater weight to the poorest person's poverty than to the next poorest person's poverty and so on. One such weighting scheme would be to say that a household 60 per cent below the poverty line receives a weight of 60 per cent, one 20 per cent below the poverty line receives a weight of 20 per cent, etc. These weights correspond to the $\mathrm{Pa}$ index with a equal to 2 .

When a equals 1 , we no longer give a larger weight to larger poverty gaps; each income shortfall is weighted the same. The formula for Pa simplifies to:

$$
\mathrm{P} 1=\mathrm{HI}
$$

With the Pi measure, income inequality among the poor is deemed irrelevant.

Finally, when a equals 0 , each term in the summation is equal to 1 and the poverty index is the ratio of the number of poor (q) to the total population (n),

$$
\mathrm{p}_{0}={ }_{\mathrm{q}} / n=\mathrm{H}
$$

that is, the head-count ratio.

So what is attractive about the $\mathrm{P}_{\mathrm{a}}$ class is that it can allow for larger poverty gaps to be given greater weight while nesting $\mathrm{HI}$ and $\mathrm{H}$ as special cases.

\section{How Has The Extent Of Poverty Changed Over Time?}

Reports on countries' development performances and prospects typically go into great detail about various aspects of macroeconomic conditions (growth, investment, balance of payments, etc.) but only infrequently do they present data on how the extent of poverty has changed over time in a country. This is a critical question. In my view, the change in poverty over time is the single most important indicator of whether development is taking place and, if so, by how much.

After reporting on how the extent of poverty has changed over time, the next step should be to try to relate the observed increase or decrease to the country's economic growth experience. Was the country growing? How fast? Or was it experiencing economic decline, as many developing countries were? The reason for wanting to know this is to be able to forecast whether a resumption of economic growth is likely to improve socioeconomic conditions for the poor or not. On this, there are two schools of thought.

One is the pro-growth school. This group includes those who believe that the larger the economic pie, the more there will be for all, including the poor. Most mainstream development economists belong to this group.

The other is the anti-growth school. This group, especially prevalent among Latin Americans and Latin Americanists, includes those who believe that growth under present conditions is so unequal that the poor will lose from the process - for instance, by disproportionate increases in 
the prices of essential commodities. The pro-growth and anti-growth groups often argue with one another on the basis of precious little hard data.

Fortunately, we now have evidence on this using the national poverty lines (Fields, 1990, 1991; World Bank, 1990). The good news is that nearly always, when economic growth has taken place, poverty rates have gone down. ${ }^{4}$ The bad news is that in many developing countries economic growth has not taken place, so poverty rates have not gone down.

Taking the good news first, the World Development Report 1990 notes that poverty (as measured by the head-count index using a country-specific poverty line) decreased in the long run (defined as ten or more years) in Indonesia, Thailand, Pakistan, Brazil, Malaysia, Singapore, Costa Rica, Colombia, India, Sri Lanka and Morocco. Fields (1991), also using the head-count index and country-specific poverty lines, reports that poverty decreased in 14 countries (Brazil, Costa Rica, Hong Kong, India, Indonesia, Korea, Malaysia, Mexico, Pakistan, Puerto Rico, Singapore, Sri Lanka, Taiwan and Thailand). Without exception, over the longer run, when economic growth was positive, poverty rates fell.

But some countries suffered recessions/depressions/crises (Fields, 1990; World Bank, 1990). In Latin America and the Caribbean, poverty increased during economic declines in Costa Rica from 1979 to 1982, in Guatemala from 1979 to 1986, in Jamaica in the 1970s and in Venezuela from 1982 to 1987, while growth virtually ceased and poverty rates did not fall in Brazil and Colombia in the 1980s. Elsewhere, the evidence also points to increasing poverty in Yugoslavia from 1978 to 1987 and in Poland during those same years. For many countries, the statistics thus support the unhappy conclusion that the 1980s were a lost decade owing to a lack of economic growth. ${ }^{5}$

Based on this evidence, it is reasonable to forecast that if economic growth could be resumed, poverty rates would once again fall. This is despite the very unequal base on which most Latin American countries and many others grow. Equalising the base would probably speed the rate of improvement in the living standards of the poor. Unfortunately, political factors often prevent such changes.

The positive effects of growth on poverty have not always been appreciated. Here are some possible reasons why. One is that many development professionals were taught at their university that 'when economic growth takes place, income distribution tends to get worse before it gets better'. Not everyone would have been taught that the term 'income distribution' in that sentence refers to inequality in the distribution of income and not to how many people receive how much real income (which is the way a statistician would ask about the distribution of a variable). Few would have been told that the central tendency is a weak one and that replacing 'tends to' by 'must' would grossly misrepresent the facts. And even those who read the sentence to mean 'inequality may increase before it decreases' may have inferred that increasing inequality means that the poor are getting poorer. This does not recognise the other possibility: that inequality may increase because the incomes of the non-poor are rising faster than the incomes of the poor but the incomes of the poor are rising also.

Here again, we have evidence (Fields, 1990), and the evidence is remarkably unsupportive of any generalisation about changes in income inequality in relation to economic growth. Inequality does not tend to increase before it decreases; developing countries are divided almost evenly between those in which inequality is increasing and those in which inequality is decreasing. Inequality does not tend to increase more often in the poorer developing countries than in the richer ones; inequality increases the same proportion of the time in the two groups of countries. Inequality does not tend to increase more frequendy the more rapid is a country's rate 
of economic growth; the country's growth rate is statistically insignificant. And a high initial degree of income inequality does not result in a higher subsequent rate of economic growth; the degree of inequality at the beginning of a time period is not a statistically significant determinant of the amount of growth that takes place during the period.

In fact, as regards inequality, only one generalisation emerges - and it is that nearly any change in inequality that has taken place has been very small unless a country experienced a major change in socioeconomic structure (as in Cuba or China). Apart from that, the changes in inequality are mere wiggles: Brazil's inequality will continue to move up or down slightly around internationally high levels, Costa Rica's around intermediate levels, and Taiwan's (China) around low levels - but their paths will never cross.

\section{Conclusions}

The preferred poverty definition would have a number of characteristics. It would be scientifically based. It would measure consumption including imputations for home-produced goods, non-wage fringe benefits and the like. It would take the household as the recipient unit and adjust for family size. The time period covered would be neither too long or too short - a week or a month would be about right. It would differentiate regionally only if cost of living differences were very large. It would adjust for inflation but not for economic growth.

When computerised income distribution information is available, two comprehensive measures - the Sen index and the Pa class - can and should be calculated.

Because the ideal (a comprehensive poverty measure applied to an internationally comparable poverty line) has not been possible, the practical alternative is to measure poverty change with a head-count index applied to country-specific poverty lines. Multi-country studies using such a methodology have shown that all income groups have benefited from economic growth (and have been hurt by economic decline) approximately in proportion to where they started. (This is why inequality is essentially unchanged, even in the face of fairly high rates of economic growth or decline.) If growth is positive and if the initial structure is a very unequal one, the poor will get a relatively small share of the benefits. But they are still benefiting in absolute terms; growth does not increase their misery, macroeconomic deterioration does.

\section{Notes}

1. Specifically, this chapter is about 'absolute poverty' and not about 'relative poverty' or 'inequality', although some discussion of relative inequality appears in section 4.

2. The difference between 'family' and 'household' is that 'family' denotes a group of individuals related by blood or marriage whereas 'household' includes not only nuclear families but also groups of families or unrelated individuals living together and pooling their resources for purposes of meals and lodging (e.g. extended families).

3. For terminological convenience, it is supposed that the poverty line is defined on the basis of household income per capita, so that 'households' and 'incomes' are referred to in what follows.

4. The only notable case in the developing world in which poverty was found not to have gone down during an episode of substantial economic growth was in the Philippines under Marcos. There, the simplest explanation - crony capitalism - would appear to be the best one. 
5. The same conclusion is thought to hold for Africa, but the database is too meagre to support or refute any such claim.

\section{References}

CEPAL. 1990. Magnitud de la Pobreza en America Latina en los Alios Ochenta. 1990.

Fields, Gary S. 1990. Poverty and inequality in Latin America: Some new evidence, Paper presented at the Symposium on Urban Poverty in Latin America, Woodrow Wilson Center, Dec. 1990.

1991. 'Growth and income distribution', in G. Psacharopoulos (ed.), Essays on Poverty, Equity and Growth. Oxford, Pergamon Press.

Foster, James; Greer, Joel; Thorbecke, Erik. 1984. 'A class of decomposable poverty measures', in Econometrica, Vol. 52, No. 3, May 1984.

Sen, Amartya K. 1976. 'Poverty: An ordinal approach to measurement', in Econometrica, Mar. 1976.

United Nations Development Programme, Human Development Report 1990. Oxford and New York, Oxford University Press.

United States Congress, Committee on Ways and Means. 1991. 1991 Green Book. US Government Printing Office.

World Bank. 1990. World Development Report 1990. New York, Oxford University Press. 